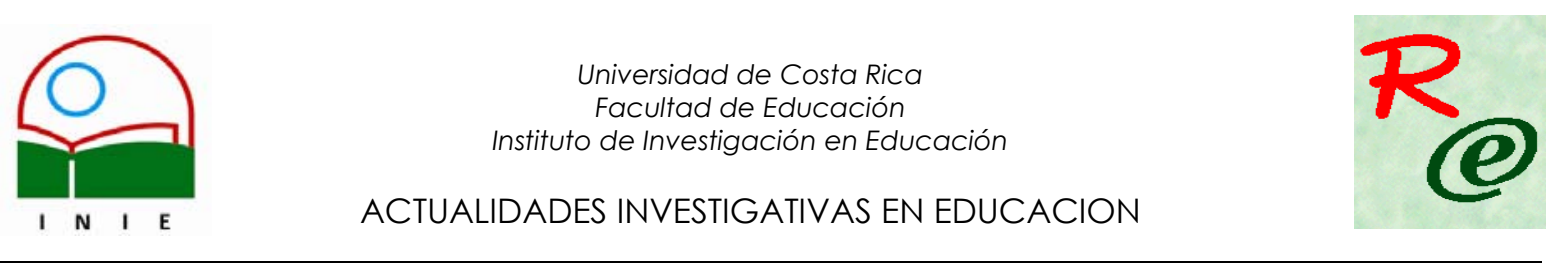

\title{
PERSPECTIVAS SOBRE LA COMUNICACIÓN
}

\author{
María Luisa Naranjo Pereira ${ }^{1}$
}

\begin{abstract}
Resumen: Existen diversas teorías, enfoques y modelos de comunicación; de cada uno de ellos pueden rescatarse aspectos de gran valor para el logro de una comunicación eficaz. Este documento presenta una revisión de esos aspectos, para que se pueda comprender mejor y enriquecer uno de los procesos más importantes para el ser humano: el proceso de comunicación. Este es un ensayo en el cual se da a conocer la posición de la autora sobre el tema abordado.

Se rescata el acento del enfoque humanista en la relación humana y en las etapas donde se desarrolla. A partir de la comunicación pragmática, se analizan los axiomas comunicacionales en que se fundamenta y lo que se conoce como patologías de esos axiomas. Además se revisan las principales características que distinguen la asertividad en la comunicación y las distintas formas de manipulación que la entorpecen. Del enfoque de Virginia Satir, se presentan los diversos aspectos de la comunicación, tanto funcional como disfuncional y los modelos de comunicación propuestos por esta autora.

Se revisan aspectos importantes del enfoque de la comunicación educativa, tales como el control de la distancia, la voz y el cuerpo, las palabras y el situacional; así como los elementos que bloquean el proceso de comunicación y las sugerencias acerca de formas correctas de escuchar. Además, se hace referencia a la necesidad de emplear procesos educativos más holísticos y constructivistas y una comunicación-interrelación horizontal y con equidad.
\end{abstract}

Palabras clave: COMUNICACIÓN HUMANISTAI COMUNICACIÓN PRAGMÁTICA/ COMUNICACIÓN ASERTIVA/ COMUNICACIÓN EDUCATIVA/ ENFOQUE DE VIRGINIA SATIR/

\begin{abstract}
Each of the diverse theories, approaches, and models of communication can provide valuable elements for the attainment of effective communication. This article presents a review of those elements with the goal of providing a better understanding and enhancement of one of the most important processes for human beings: the process of communication. This essay presents the author's position on the topic.

The importance given to human relationships and the stages through which these develop, is a contribution of the humanistic approach. Pragmatic communication provides basic axioms and what is known as the pathology of those axioms. The major characteristics that distinguish assertive communication from various forms of manipulation that obstruct it are discussed. In addition there is reference made about several aspects of functional and dysfunctional communication according to Virginia Satir.

Suggestions from the approach of educational communication are examined, giving special attention to the use of body language and situational control, as well as to blocks to communication and to recommended ways of listening. Besides that, a reference is make for the need of using more holistic and constructive educational processes and a communication based on equity and horizontal relationships.
\end{abstract}

Keywords: HUMANISTIC COMMUNICATION/ PRAGMATIC COMMUNICATION/ ASSERTIVE COMMUNICATION/ EDUCATIONAL COMMUNICATION/VIRGINIA SATIR'S THEORETICAL APPROACH/

\footnotetext{
1 Licenciada en Ciencias de la Educación con énfasis en Orientación, Profesora de Psicología, ambos títulos de la Universidad de Costa Rica. Profesora de la Escuela de Orientación y Educación Especial en la Universidad de Costa Rica, durante los últimos 22 años. Ha publicado diversos artículos relacionados con el Desarrollo Humano y la superación personal y tres libros de texto: Enfoques conductistas, cognitivos y racional-emotivos, Enfoques humanísticos-existenciales y un modelo ecléctico, y Estrategias para la Orientación de la niñez.
}

Correo electrónico: mInaranjo@costarricense.cr

Artículo recibido: 29 de abril, 2005

Aprobado: 31 de octubre, 2005 


\section{El enfoque humanista de la comunicación}

Desde el punto de vista humanista, el componente básico del proceso de comunicación humana es el ser humano y, la función básica de esta comunicación, consiste esencialmente en desarrollar relaciones, más que en intercambiar información.

La unidad básica del proceso de comunicación humana, es la retroalimentación y el resto del modelo se organiza alrededor de esa unidad. Además, desarrolla un énfasis en la capacidad autorreguladora de la persona, lo que implica libertad de elección y afirmación del propio ser.

Otra característica del modelo humanista de comunicación es la importancia de que toda comunicación tiene lugar en un contexto, que está conformado por tres aspectos: el cultural, el situacional y el de urgencia.

El aspecto cultural del contexto, dentro del cual tiene lugar la comunicación humana, se relaciona con el marco de referencia actitudinal que la persona desarrolla durante toda su vida. Es decir, toma en cuenta todas las creencias, los temores, los deseos y las expectativas que la persona ha desarrollado, como resultado de su exposición a la cultura dentro de la cual vive. Los aspectos situacionales del contexto son todas las variables psicológicas, sociológicas y físicas; por ejemplo el tiempo, el sexo o la edad de la persona. El tercer aspecto es el de urgencia, el cual se vincula con la necesidad de comunicar o el requerimiento de una clase específica de comunicación e incluye todas las presiones internas, las restricciones y las necesidades que sentimos en cualquier acontecimiento comunicativo.

De acuerdo con Bateson (1984) el concepto de comunicación incluye todos los procesos mediante los cuales los seres humanos se influyen mutuamente. La comunicación hace posible la relación entre las personas y está determinada por el contexto en el que se produce; es decir, toda comunicación exige un contexto, por que sin éste no hay significado.

Borden y Stone (1982, p. 82) señalan que:

Es posible describir la comunicación como un deporte de contacto. Se trata de la única manera de que disponemos para ponernos en contacto con los demás y, aún cuando 
no nos demos cuenta de cuánto dependemos de ella, constituye el centro de nuestra existencia. Nuestros sentidos captan las señales transmitidas por otros y a partir de ellas creamos significados.

El significado compartido permite que alguien tenga una parte o use algo que nos pertenece. Se comparte tiempo, energía, emociones y, al mismo tiempo, se aumenta o prolonga la vida de lo compartido, las ideas, experiencias, amor. Cuando se comparten experiencias con otra persona, se produce una relación, por tanto, comunicarse es relacionarse y relacionarse es comunicarse.

Según Maturana en Eliot (2003), los sentimientos y las emociones son fundamentales para que exista una comunicación real; es decir, la comunicación es básicamente interrelación y a partir de ésta emergen múltiples estrategias para el desarrollo y la solución de la diversas situaciones humanas. La verdadera comunicación surge entonces de la empatía, del auténtico acercamiento entre las personas que participan en una sociedad.

\subsection{Etapas en las que se desarrolla una relación}

En el enfoque humanista se emplea el concepto de "intensidad del envolvimiento" para indicar la forma en que se desarrolla una relación. La primera etapa es la del reconocimiento que ocurre muchas veces al día. Así, cuando nos cruzamos con alguien en la calle y nuestras miradas se encuentran, saludamos con la cabeza o diciendo jhola!, hemos reconocido a esa persona como otro ser existente. Sin embargo, si no reconocemos a otra persona como tal, simulando que no está allí, también le estamos comunicando el hecho de que no queremos siquiera empezar la relación.

La siguiente es la etapa de aceptación del envolvimiento, la cual es más intensa, pues la aceptación significa deseo de conocerse. Conforme se desarrolla esta etapa, se debe encontrar más de nosotros y de nosotras mismas y de nuestras experiencias que podamos y estemos dispuestos y dispuestas a compartir con otras personas.

Cuando se pasa de la etapa de aceptación a la de afecto, la comunicación tiene muchas más experiencias significativas, pues se está más entregado a este envolvimiento. Tal vez se exploren los sentimientos mutuos, se indague cuáles son los pensamientos y emociones de cada persona para determinar su profundidad y se trate de averiguar el límite de la 
franqueza de cada una. Esta es la etapa de comprensión. En ésta, la profundidad de la relación dependerá, en gran medida, de lo que averigüe cada persona sobre la otra.

\section{Teoría de la comunicación pragmática}

En la teoría de la comunicación pragmática, presentada por Watzlawick (1991), se define la comunicación como un proceso que transmite información y afecta a otras personas.

De acuerdo con Bateson y Ruesch (1984), el concepto de comunicación incluye todos los procesos mediante los cuales las personas se influyen mutuamente. Todas las acciones y los eventos se convierten en aspectos comunicativos tan pronto como son percibidos por el ser humano; esto implica, que tal percepción modifica la información que una persona poseía y, por lo tanto, influye en ella.

Se considera que en la comunicación se da interacción, sea ésta interpersonal o con diferentes aspectos del ambiente físico y social, lo que permite el intercambio de información. Por esto toda interacción es comunicación.

Estos mismos autores mencionan que las impresiones recibidas provenientes de lo que nos rodea, de las otras personas y de nuestro organismo, así como la retención de esas impresiones, como referencia para la acción futura, pueden ser consideradas como parte integral del sistema de comunicación personal.

Watzlawick (1991) conceptualiza la comunicación en varios axiomas comunicacionales, los cuales se relacionan, a su vez, con diferentes trastornos que pueden desarrollarse en la comunicación humana y a los que se les denomina como comunicación patológica. A continuación, se presenta un resumen de algunos de estos axiomas.

\section{Axioma metacomunicacional. "No es posible no comunicarse".}

Esto significa que en la medida en que por lo menos dos personas se den cuenta cada una de la presencia de la otra, se establecen líneas de comunicación de las que es imposible abstraerse. Es decir, que si por lo menos dos personas son conscientes de la presencia una de la otra y aunque alguna de ellas no desee entablar conversación, en la medida en que una de ellas se exprese mediante conductas, hace que la otra persona interprete esa conducta. Así, ambas se afectarán mutuamente y sus conductas se verán modificadas por 
este círculo de relación. Por tanto, la actividad o inactividad, las palabras o el silencio, presentan un valor de mensaje.

\subsection{Patología del primer axioma}

Las personas pueden emplear distintas formas para detener, al menos intencionalmente la comunicación. Algunas de estas formas son:

\subsection{Rechazo}

Este se da cuando una persona responde a otra en términos de "no me hable; no me quiero comunicar con usted". No obstante, en ese intento de no comunicarse, le está comunicando que no desea interrelacionarse.

\subsection{Aceptación de la comunicación}

En este caso, la persona termina por ceder y entablar conversación, pero una vez que ha empezado a responder, le resultará cada vez más difícil detenerse. Esto se conoce como "lavado de cerebro".

\subsection{Descalificación de la comunicación}

La descalificación se presenta cuando una de las personas comunicantes evade la relación que la otra trata de entablar, restándole importancia al nivel del contenido. Por ejemplo, ante la pregunta ¿cómo te llamas?, la respuesta podría ser: ¡qué frío hace hoy!. Al quitar importancia al contenido del mensaje, define también, en el nivel de relación, los términos de la comunicación, pues el mensaje no verbal indica que no le interesa comunicarse con usted.

\subsection{El síntoma}

Otra respuesta que la persona puede emplear para no entablar relación con otra, es el síntoma; por ejemplo, puede fingir somnolencia, sordera, desconocimiento del idioma o cualquier otra incapacidad que sirva para justificar la imposibilidad de comunicarse. En estos casos, el mensaje sería: "no me molestaría hablarle, pero algo más fuerte que yo, de lo cual no puede culparme, me lo impide". 


\section{Axioma: "Toda comunicación tiene un aspecto de contenido y un aspecto relacional, de forma tal que el segundo califica al primero y, es por ende, una metacomunicación."}

En este axioma, se destacan dos aspectos, el de contenido y el de relación. El aspecto de contenido es el que transmite información. Se refiere al tema que se trata. El aspecto de relación puede ser trasmitido por la conducta no verbal, por ejemplo, el tono o fuerza que se da al contenido; la forma en que se dicen las cosas; los gestos, expresiones y movimientos corporales utilizados al expresar los mensajes. Este aspecto comunica cómo debe entenderse el mensaje y cómo la persona que lo envía percibe su relación con la persona que lo recibe. Este aspecto relacional es una comunicación acerca de la comunicación.

Para la persona orientadora, el aspecto relacional es muy importante, pues define la forma cómo las personas se van a comunicar.

\subsection{Patología del axioma}

En el mejor de los casos, las personas participantes están de acuerdo con el contenido de sus comunicaciones y con la definición de su relación. En el peor de los casos, se presenta la situación inversa, es decir, las personas están en desacuerdo con los aspectos de contenido y también con los de relación. Entre estas dos situaciones extremas, existen diversas formas mixtas importantes, entre estas:

a. las personas están en desacuerdo con el aspecto de contenido, pero esto no perturba su relación.

b. las personas están de acuerdo con los aspectos de contenido, pero no en los de relación.

c. existen confusiones entre los dos aspectos: contenido y relación. Esta confusión puede consistir en un intento por resolver un problema relacional en el nivel de contenido, donde no existe o, por el contrario, en una reacción frente a un desacuerdo objetivo con una variación de reproche básico, por ejemplo: "si me amaras, estarías de acuerdo conmigo."

d. aquellas situaciones en las que una persona se ve obligada a dudar de sus propias percepciones en el nivel de contenido, con el propósito de no poner en peligro una relación con otra persona. 


\section{Axioma: "la naturaleza de una relación depende de la puntuación de las secuencias de comunicación entre las personas comunicantes."}

Este aspecto de la puntuación se refiere a la forma cómo se organiza o se conceptualiza el intercambio entre dos o más personas. La organización permite indicar quién inicia el intercambio en la comunicación, por ejemplo, quién posee la iniciativa, el dominio o la dependencia al establecer una relación. El problema surge del hecho de que las personas no verbalizan, de manera explícita, su forma de organizar la relación.

\subsection{Patología del axioma}

Watzlawick (1991, p. 93-94), presenta el siguiente ejemplo para ilustrar la forma en que se pueden presentar los trastornos de comunicación relacionados con este axioma:

P escribe una carta a $\mathrm{O}$, proponiéndole un negocio e invitándolo a participar. O acepta la proposición, pero su carta no llega a su destino. Después de un tiempo, P llega a la conclusión de que $\mathrm{O}$ no ha tenido en cuenta su propuesta y a su vez, resuelve no interesarse más por él. Por otro lado, $O$ se siente ofendido, porque no tuvo contestación a su carta y también decide no establecer nuevo contacto con P. A partir de este momento, su disputa silenciosa puede durar eternamente a menos que se decidan a investigar que sucedió con sus comunicaciones, esto es, a menos que comiencen a metacomunicarse. Solo entonces averiguarán que $P$ no sabía que $O$ había contestado.

\section{La asertividad en la comunicación}

El entrenamiento para lograr una conducta y una comunicación asertiva, fue una de las primeras técnicas desarrolladas por los terapeutas de la conducta en la década de 1950 y comienzos de la década de 1960, de acuerdo con Janda (1998). La palabra asertivo, de aserto, proviene del latín assertus y significa: afirmación de la certeza de una cosa, por lo que se deduce que una persona asertiva es aquella que afirma con certeza.

Existen diversas definiciones de asertividad. Ciertos autores consideran la asertividad como la conducta que posibilita la disminución de la ansiedad; otros la consideran como la defensa de los derechos propios y algunos como la habilidad para expresar sentimientos y pensamientos. Riso (1988, p. 45) define la conducta asertiva como: 
Aquella conducta que permite a la persona expresar adecuadamente (sin distorsiones cognitivas o ansiedad y combinando los componentes verbales y no verbales de la manera más efectiva posible) oposición (decir no, expresar desacuerdos, hacer y recibir críticas, defender derechos y expresar en general sentimientos negativos) y afecto (dar y recibir elogios, expresar sentimientos positivos en general) de acuerdo con sus intereses y objetivos, respetando el derecho de los otros e intentando alcanzar la meta propuesta.

Como puede notarse, el concepto de asertividad es multidimensional. Este término "asertividad" es definido por Neidharet y otros (1989, p. 115), como: "la confianza puesta en nuestra propia persona, en nuestras opiniones, en nuestros derechos $y$ en nuestras reclamaciones. Es decir, es una firmeza que emana de la propia personalidad, es una autoafirmación personal". Cuando se posee esa firmeza, se aceptan sinceramente los sentimientos propios y se expresan ante los demás de una manera segura y abierta.

La asertividad permite hacernos responsables de nuestros sentimientos y de la forma en que nos demos a conocer a las demás personas. Significa que sentimos respeto por ellas a la vez que respetamos nuestra propia persona.

Las personas asertivas tienen capacidad para reconocer sus necesidades y hacerlas saber con confianza y claridad. Aceptan que las demás tienen el mismo derecho que ellas de hacerse valer $\mathrm{y}$, por este motivo, presentan sus ideas o reclamaciones con toda cortesía y escuchan con el mayor respeto las reclamaciones que les presentan otras personas.

Se considera que la sinceridad es la característica más distintiva de las personas asertivas. Aman y defienden la realidad $\mathrm{y}$, por eso, narran los hechos según ocurrieron, sin distorsiones, exageraciones, autoalabanzas ni vanaglorias. Buscan el conocimiento real, no las ilusiones. Desean saber quiénes son ellas en realidad y quiénes son en realidad las personas que les rodean. La base de la asertividad personal consiste en afirmar el verdadero yo, no algún otro yo inventado para embaucar a las demás personas.

La falta de asertividad conlleva, generalmente, falta de respeto a las demás personas o mala fe, o ambas cosas a la vez, como sucede en la manipulación. Las personas que no desean o tienen temor de manifestarse y hacerse valer, por lo general, traman algo para 
conseguir lo que quieren. Este tipo de actitudes se pueden convertir en algo muy serio, cuando una persona solo ve a las demás, como aquellas a las que hay que vencer o superar con la burla, la mentira o el ingenio. Se puede manipular a las personas de diferentes maneras. Algunas de estas formas, sobre las cuales hacen referencia Neidharet y otros (1989) son las siguientes:

\subsection{La agresividad o intimidación}

La forma más común de falsa asertividad es la agresividad, que a menudo solo constituye una fachada que oculta una debilidad interior. Una conducta es agresiva, cuando la expresión de pensamientos, sentimientos y opiniones se hace de manera inapropiada e impositiva, transgrediendo los derechos de otras personas. La asertividad y la agresividad pertenecen a dos categorías distintas, de manera que una persona que se hace más asertiva, no tiene razón para hacerse más agresiva. De todas formas, la comunicación clara y sincera de las necesidades personales, tiene más probabilidades de merecer el respeto de las demás personas y de conseguir lo que se desea.

\subsection{El desvalimiento}

Es lo contrario de la agresividad. En lugar de alimentar temores con su conducta agresiva y sus amenazas violentas, las personas desvalidas hacen un llamado a nuestra voluntad, simpatía o piedad. Estas personas en vez de pedir las cosas en forma directa, han aprendido a emplear pequeñas, pero frecuentes llamadas de atención, como "ayúdame, yo no puedo", para satisfacer sus necesidades. El problema es que esta forma de actuar resulta en una anulación de la autoestima de esas personas.

Con este tipo de conductas pasivas, se transgreden los derechos propios, al no ser capaz de manifestar en forma abierta los pensamientos, sentimientos y opiniones o, bien, al expresarlos con falta de confianza o como autoderrota.

\subsection{La culpabilidad}

La persona manipuladora puede intentar despertar un sentimiento de culpabilidad para obligar a otra a actuar de cierta manera. Este tipo de manipulación consiste básicamente en acusaciones de egoísmo o en la reclamación de ciertos deberes u obligaciones. 


\subsection{La crítica}

Esta es otra forma de manipulación. El objetivo que se persigue con la crítica es poner a la otra persona a la defensiva, evitando que siga poniendo su atención en quien critica. Este tipo de persona muy pocas veces trata de ofrecer un consejo constructivo.

Algunas veces, la crítica se utiliza como una manera indirecta de persuadir, cuando se avergüenza o se pone en ridículo a alguien para que haga algo que no desea realizar. Un ejemplo sería el joven o la joven que sus compañeros o compañeras tratan de cobarde, si no comparte con ellos o con ellas una aventura arriesgada.

\subsection{Dudar de nuestros motivos.}

Se sugiere estar muy alertas, cuando se nos formulen preguntas sobre algo que hemos hecho y que empiecen con ¿por qué?. Probablemente quien pregunte desea criticar nuestra decisión o nuestras razones, pero no posee el valor para criticarnos directamente. $O$ bien, puede que esa persona se sienta con derecho de recibir una explicación y desee que le presentemos alguna excusa o nuestras disculpas.

\section{La comunicación según Virginia Satir}

Menciona Satir (1980), que en general la palabra comunicarse se refiere tanto a la conducta no verbal como verbal, dentro de un contexto social. Entonces la comunicación significa “interacción" o "transacción”. El concepto comunicación incluye también todos los símbolos y claves que las personas utilizan para dar y recibir un significado.

Para que las personas obtengan la información que necesitan deben comunicarse con claridad. Sin esta comunicación, no se podría sobrevivir, pues se necesita conocer acerca de los hechos del mundo, de las otras personas y de las relaciones con éstas. Para recibir esta información, se cuenta con dos métodos básicos: pedir respuestas verbales y observar la conducta no verbal.

Es importante destacar que las personas investigadoras estiman que, en un mensaje, menos de la mitad de su significado se transmite de forma verbal. La postura del cuerpo, los contactos, los gestos, el tono de voz, así como el entorno físico son con frecuencia mucho más importantes que las palabras pronunciadas. 
Las palabras que se emplean, el énfasis o la inflexión que se les dé, transmiten una gran cantidad de comunicación. Pero también se comunica sin pronunciar palabras, como el fruncir las cejas; cruzar los brazos; mirar al suelo mientras se habla; consultar el reloj; hacer señales o sonrojarse.

Algunas conductas no verbales transmiten una idea, por ejemplo, poner el dedo índice sobre los labios en un gesto de silencio; la sonrisa o golpear con el puño sobre la mesa. Por tanto, el lenguaje corporal es con frecuencia más espontáneo que las palabras y puede transmitir, con mayor claridad, lo que se intenta comunicar.

En la simple comunicación verbal se presentan diferentes dificultades. Para empezar, la misma palabra puede ofrecer diferentes significados. Este aspecto elemental de la comunicación es muy importante, porque las personas con frecuencia tienen conflictos debido a que una utilizó una palabra en un sentido y la otra escuchó como si quisiera decir algo diferente. Por lo tanto, debido a que las palabras por sí mismas suelen ser confusas, es importante que la persona aclare lo que dice y que a su vez pida a las demás que hagan lo mismo cuando se siente confundida por lo que ha escuchado.

Satir (1980) señala que las personas pueden comunicarse de una manera funcional; esto es, eficaz y armónicamente, o de manera disfuncional. Se dice que una persona es disfuncional, cuando no ha aprendido a comunicarse en forma apropiada. Esto por cuanto no se percibe ni se interpreta a sí misma en forma correcta y tampoco lo hace con los mensajes que le llegan del exterior. Las suposiciones en las que basa sus actos, son defectuosas y sus esfuerzos por adaptarse a la realidad son, por lo tanto, confusas e inapropiadas. Por el contrario, una persona que se comunica de una manera funcional, puede expresar con firmeza su opinión, aclarar lo que dice, esperar una réplica y aceptar ésta cuando la recibe.

Esta autora se refiere también a algunas características de las personas que se comunican disfuncionalmente. Por ejemplo: suponen que las demás comparten sus sentimientos y percepciones ("desde luego que a él no le gustaría esto"); que sus percepciones o evaluaciones son completas; que lo que ellas perciben o evalúan no cambiará ("siempre ha sido así). Suponen además que las características que atribuyen a las cosas o a las personas son parte de esas cosas o personas ("ella es agresiva"), que pueden entrar en la 
mente de las otras, ("sé lo que estás pensando") y que la otra, a su vez, puede entrar en su mente ("tú sabes lo que en realidad quiero decir").

Si la persona que recibe el mensaje es tan disfuncional como la que lo envía, responderá asintiendo o desintiendo. Pero si es funcional, primero pedirá a quien envía el mensaje que lo aclare. Por ejemplo: ¿Cómo llegó a la conclusión de que esa obra es mala? ¿En qué se basa para opinar así de esa persona? ¿Qué quiere decir al expresar que "todos son iguales"? ¿Por qué cree que usted sabe lo que yo pienso y siento?

Una vez que la persona recibe esta petición de aclarar, tal vez decida contestar, si es una comunicadora funcional: "permítame que le explique de distinta manera"; "voy a darle algunos ejemplos que aclaren mi posición."

No obstante, si quien envía originalmente el mensaje es un comunicador o comunicadora disfuncional, utiliza de nuevo formas que tienden a bloquear el análisis del asunto. Por ejemplo "usted sabe muy bien lo que quiero decir".

Otras características de la persona que se comunica disfuncionalmente, señaladas por esta autora, se presentan cuando: se comporta como si no se diera cuenta del hecho de que generaliza o de que actúa basándose en suposiciones; envía mensajes incompletos ("como puedes ver...bueno es obvio"); suprime en sus mensajes fragmentos enteros que sirven de conexión y, con frecuencia, no envía mensaje alguno, pero se comporta, en relación con otras, como si lo hubiera hecho.

De esta forma, quien comunica disfuncionalmente no solo deja a la persona que recibe el mensaje adivinando, sino que actúa basado en la suposición de que, en efecto, se comunicó bien. La persona que recibe el mensaje, a su vez, actúa basándose en lo que trata de adivinar. Por lo tanto, es muy fácil que se malentiendan.

En síntesis, señala Satir (1980, p. 78) que:

Si se quiere que la comunicación verbal sea razonablemente clara, tanto el emisor de un mensaje como el receptor tienen la responsabilidad de hacer que así sea. a. La aclaración y la clarificación mutuas reducen las generalizaciones. Permite a ambas partes ser específicas y probar sus afirmaciones. Permite a una persona verificar su 
realidad y compararla con la realidad de las otras personas. b. También ayudan a separar a quien percibe las cosas de lo que está siendo percibido. Frena la tendencia a proyectar en otros los propios deseos, pensamientos y percepciones. Frena los esfuerzos de una persona de hablar por otra.

Por su parte, Neidharet y otros (1989, p. 105) sugieren cuatro formas para mejorar la comunicación no verbal, estas son:

* Mirar directamente a los ojos a la persona con la que se está hablando, para transmitir un auténtico interés y la atención que se presta, tanto a lo que ella tiene que decir, como al propio punto de vista.

* Colocarse frente a la persona con la que se está hablando e inclinarse ligeramente hacia ella.

* Mover las manos de forma apropiada. La expresión facial corresponde con el sentido de la conversación y las palabras que se pronuncian. Algunas personas, a veces, ríen cuando están enfadadas o bromean, cuando quieren decir algo desagradable. En principio, estas formas de comunicación son poco sinceras y generan desconfianza.

* Prestar una atención especial al nivel y al tono de la voz. Un tono de voz firme y equilibrado puede ser muy eficaz para comunicar confianza en sí mismo o en sí misma. Un tono suave y agradable comunicará cariño y afecto, mientras que una voz quejumbrosa y nasal puede asustar a la persona que escucha.

Es importante reiterar que cuando se juzga si una comunicación es clara, se debe recordar que las personas se comunican de diversas formas, además de emplear palabras, lo hacen mediante sus ademanes, su expresión facial, su postura y movimientos corporales, su tono de voz e, inclusive, por la manera cómo están vestidas.

Además, toda comunicación ocurre dentro de un contexto; es decir, se debe tomar en cuenta cuándo sucede, dónde, con quién, bajo qué circunstancias y cuál es la relación entre las personas que realizan el intercambio.

Todo esto hace que la comunicación sea un asunto complejo. La persona que recibe el mensaje debe evaluar todas las formas diferentes de cómo la otra envía mensajes $\mathrm{y}$, al mismo tiempo, debe estar consciente de su propio sistema de recepción; es decir, de su propio sistema de interpretación. Así, cuando una persona habla, la otra evalúa el significado 
verbal del mensaje recibido; escucha el tono de la voz de quien habla; observa lo que hace, es decir, su lenguaje corporal y las expresiones faciales que acompañan el mensaje y evalúa lo que la otra está diciendo dentro de un contexto social.

Por otra parte, lo que la persona quiere decir en su comunicación, tiene por lo menos dos niveles; el denotativo o contenido literal y el metacomunicativo, que se refiere a un comentario acerca del contenido literal y acerca de la naturaleza de la relación entre las personas participantes de la interacción. Señala Satir (1980, p. 85) que la metacomunicación "es un mensaje acerca de un mensaje". Transmite la actitud de la persona hacia el mensaje que acaba de enviar: "el mensaje que envié era amistoso". Transmite la actitud, los sentimientos y las intenciones de la persona hacia quien envía el mensaje: "Te veo como a alguien con quien puedo ser amigable".

Se pueden emplear metacomunicaciones no verbales como fruncir el ceño, hacer muecas, sonreír, ponerse rígido o dejar caer los hombros. También se pueden enviar metacomunicaciones verbales, explicando con palabras su propio proceso de enviar mensajes.

Explica esta autora que algunas personas pueden:

a) rotular el tipo de mensaje que envían, cuando se dice a la otra con cuánta seriedad desea que el mensaje se reciba y cómo quien recibe el mensaje debe responder a éste; por ejemplo: "era un chiste" (ríete de él), "fue un comentario casual" (ignóralo), "fue una pregunta" (contéstala), "fue una petición" (tómala en consideración), "fue una orden", (obedécela).

b) Puede también decir por qué envió el mensaje, al referirse a lo que la otra persona hizo. "Fuiste amable conmigo. Te estaba devolviendo el favor".

c) Puede decir por qué envió el mensaje al referirse a lo que cree que son los deseos, sentimientos e intenciones de la otra persona hacia él. "Pensé que estabas cansado y querías que te ayudara".

d) Puede decir por qué envió el mensaje, al referirse a una petición que se le hizo: "me estabas ordenando que hiciera algo, y yo no recibo órdenes"

e) Puede decir por qué envió el mensaje, al referirse al tipo de respuesta que estaba tratando de obtener: " estaba tratando de hacerte enojar"; " estaba tratando de hacerte hablar"; "estaba tratando de convencerte". 
f) Puede decir por qué envió el mensaje, al referirse específicamente a lo que estaba tratando que la otra persona hiciera o dijera o no hiciera ni dejara: "quería que fueras a la tienda en vez de ir yo"; "te estaba pidiendo que te salieras del cuarto".

\section{Modelos de comunicación}

Satir (1998) presenta cuatro modelos básicos de comunicación que las personas emplean, cuando reaccionan a la tensión y, al mismo tiempo, sienten que su autoestima está involucrada. En estos cuatro modelos de comunicación, se emplean los mensajes de doble nivel; es decir, en los cuatro casos, la voz dice una cosa que el resto de la persona contradice. Cuando la interacción es con otra persona que reacciona también con mensajes de doble nivel, los resultados suelen ser hirientes y poco satisfactorios. Este tipo de mensajes aparecen cuando una persona se subestima; teme herir los sentimientos de las demás; se preocupa por las represalias que puedan tomar las otras personas; teme la ruptura de relaciones; no desea imponerse o no da ninguna importancia a la persona o a la interacción. En casi todos estos casos la persona no se da cuenta de que está enviando mensajes de dos niveles. En general, se pueden dar las siguientes posibilidades: captar las palabras e ignorar el resto; captar lo que no se dice e ignorar las palabras; ignorar todo el mensaje cambiando el tema o comentando la naturaleza de doble nivel del mensaje.

En los cuatro modelos de comunicación, la persona siente y reacciona a la amenaza, pero como no quiere mostrar "debilidad", intenta disimular mediante las siguientes cuatro formas:

* Aplacar, de tal manera que la otra persona no se enoje;

* Culpar, para que la otra persona la crea fuerte;

* Superrazonar, mediante lo cual trata de enfrentarse a la amenaza como si fuera inofensiva y de establecer además su propio valor empleando palabras altisonantes.

* Distraer, con el fin de ignorar la amenaza, comportándose como sí no existiera.

No obstante, nuestro físico llega a adaptarse a nuestros sentimientos de autoestima, aún cuando no nos demos cuenta de ello. A continuación, se presenta una síntesis de las formas de comportamiento en cada modelo de comunicación presentado por Satir (1998):

Aplacador: la persona siempre habla para congraciarse, tratando de complacer, de disculparse, nunca está en desacuerdo en ninguna forma. Habla como si no pudiera hacer nada por sí misma y siempre necesita tener la aprobación de otras. 
Acusador: la persona siempre encuentra fallas, es autoritaria. Se siente superior a las demás y parece decir: "Si no fuera por ti, todo andaría bien". Su voz es dura, tensa y muchas veces aguda y fuerte. Su sensación interna es de tensión muscular y orgánica. Piensa que en realidad tampoco ella vale gran cosa, de modo que si alguien le obedece empieza a sentir que la toman en cuenta.

Superrazonable: la persona es en extremo razonable y correcta y no demuestra ningún sentimiento. Es calmada, fría e impenetrable. Físicamente se siente seca y distante. Su voz es monótona y sus palabras tienden a ser abstractas.

Irrelevante: la persona dice o hace cosas que tienen poca relación con lo que dicen o hacen las demás. Nunca da a conocer sus sentimientos internos. Su voz es como un sosonete, con frecuencia en desacuerdo con las palabras y puede subir y bajar el tono sin motivo alguno, porque en realidad no se dirige a nadie en particular. Su sensación interior es de confusión.

Parece que todas esas formas de comunicación se aprenden en la niñez. Conforme el niño y la niña tratan de abrirse camino a través del complicado $y$, muchas veces, amenazante mundo en que vive, emplea una u otra de estas formas de comunicación.

Existe una quinta respuesta a la que Satir (1988, p. 72), llama abierta o fluida. Señala que:

En esta reacción, todos los elementos del mensaje van en la misma dirección-la voz dice palabras que concuerdan con la expresión facial, la posición del cuerpo y el tono de voz. Las relaciones son fáciles, libres y honestas y hay pocas amenazas para la autoestima. Con esta reacción no es necesario culpar, convertirse en una calculadora, o de estar en movimiento perpetuo.

Una forma en que se puede alcanzar la meta de convertirse en una persona abierta, es conociendo algunos de los temores que impiden lograr la franqueza. Por ejemplo, señala esta autora: para evitar el rechazo que tanto tememos, tendemos a amenazarnos pensando que me podría equivocar; podría molestar a alguien; alguien me va a criticar; creerán que soy una persona molesta; van a creer que no soy una persona perfecta; él o ella podrían alejarse. 
Cuando se pueden dar respuestas como las siguientes a las afirmaciones anteriores, se habrá alcanzado una auténtica madurez. Indudablemente cometeré errores al emprender cualquier acción, especialmente si es nueva. Puedo tener la seguridad de que siempre habrá alguien a quien no le guste lo que hago; no todas las personas tenemos los mismos gustos. Si alguien me critica, en realidad, nadie es perfecto; algunas críticas son útiles. Si cada vez que me encuentro en presencia de otras personas, las interrumpo o les impongo mis puntos de vista, será algo molesto. Si pienso de mí misma como una persona que tiene que ser perfecta, es muy posible que siempre me encuentre defectos.

La respuesta abierta permite saber disculparse sin suplicar; no estar de acuerdo sin acusar; ser razonable sin ser una persona inhumana y molesta y ser capaz de cambiar el tema sin distraer. Esto brinda una mayor satisfacción personal, menos angustia y más oportunidad de crecimiento y de relaciones satisfactorias con las demás personas.

May, citado por Borden y Stone (1987, p. 206), expresa que: "La comunicación personal, es en realidad sumamente difícil y rara... nuestro destino actual es existir en un mundo en el que la comunicación entre las personas está prácticamente destruida".

Por su parte, Borden y Stone (1987, p. 210) manifiestan que: "En medio de la multitud el hombre parece estar luchando por lograr relaciones significativas con su mundo, su semejante y el mismo, tratando de aferrar lo que aquí denominamos como comunicación humana". Y agregan: el reconocimiento del "sí mismo" y de los demás como "sí mismos" por propio derecho, quizás sea el punto donde comienzan las relaciones significativas.

Bateson y Ruesch (1984) afirman que los seres humanos tienen sus propios sentimientos y sus formas de pensar, tanto en el momento en que se relacionan como después, y actúan y reaccionan unos en función de los otros, percibiendo sus propios actos, los de los otros y lo que ocurre. Las impresiones sensoriales recibidas y las conductas ejecutadas se registran, dejando huellas en el organismo y, como resultado de esas experiencias, la percepción que las personas tienen de si mismas y de las otras, puede ser confirmada, modificada o eliminada totalmente. La suma total de esas huellas, acumuladas a lo largo del tiempo por cientos de experiencias, forma el carácter personal y determina, en parte, la manera en que serán enfrentadas las situaciones futuras. 
Por otra parte, Maturana en Brusco (2001) plantea que el lenguaje más las emociones generan las conversaciones y que el ser humano se va construyendo a partir de éstas. Las conversaciones ayudan a actualizar el sí mismo, confirmando y recreando quién soy, qué desean de mí las otras personas y cómo voy ubicándome en la sociedad. Por lo tanto, resulta importante reflexionar sobre la forma en cómo nos comunicamos con las otras personas; esto es, nuestra manera de relacionarnos con quienes convivimos.

\section{La comunicación educativa}

La doctora Grant (1988) entiende la enseñanza esencialmente como un proceso de comunicación. Esta autora se refiere a cuatro elementos que provocan diferencias entre una lección interesante y otra aburrida. Estos elementos son: control de la distancia, control corporal y vocal, control de las palabras y control de la situación. A continuación se hace referencia a cada una de ellas.

\subsection{Control de distancia}

Se considera que la persona está encapsulada en una serie de espacios circulares concéntricos. El primero de estos, denominado con el término íntimo; se extiende hasta un radio de cuarenta y seis centímetros aproximadamente. Atreverse a entrar en el espacio íntimo de una persona, supone un acercamiento emocional en la relación que la gente cree tener o desea conseguir.

Se permite entrar al espacio íntimo a aquellas personas a quienes se ama y a aquellas que por su papel lo requieran, a fin de satisfacer nuestras necesidades, tales como las personas profesionales en salud.

Para el segundo círculo se utiliza el término distancia personal y es el área comprendida entre cuarenta y seis centímetros y un metro veintidós centímetros. A esta distancia, entre sus extremos, todavía es posible el contacto físico; se percibe con todo detalle el cuerpo y vestido del otro o de la otra y las personas bajan significativamente la voz al hablar a esa distancia. En las interacciones que ocurren dentro de estos límites, las personas tienen la sensación de experimentar mayor participación que en aquellas que tienen mayor distancia. La distancia personal se reserva generalmente para amigos y amigas y familiares . 
El tercer círculo es la distancia social. Esta es el espacio comprendido entre un metro veintidós centímetros y tres metros sesenta y seis centímetros. Esta es la distancia en general apropiada para los compañeros y las compañeras de trabajo, para los negocios y las conversaciones con personas poco conocidas. El área que se extiende más allá de esa distancia se llama distancia pública.

Cuando se colocan las sillas para formar un grupo de debate se constituye, de forma no verbal, el primer paso para realizar una actividad común; este hecho "nos asocia". El mismo mensaje transmite un profesor o profesora cuando acerca su silla hacia un estudiante o una estudiante, introduciéndose en su espacio personal para prestarle ayuda individualizada.

\subsection{Control de la voz y el cuerpo}

Se considera que la variación en la fuerza de la voz está en relación directa con la distancia. Así, al disminuir la distancia, se tiende a bajar la voz y, por el contrario, si se mantiene una distancia mayor, como la pública, se imprime una fuerza mayor de voz al hablar. El no ajustar la fuerza de la voz a la distancia, puede dar como resultado una disminución en la efectividad de las palabras.

El tono de voz tiene un efecto parecido. Un tono alto puede ser tan molesto que la persona que escucha puede no percibir las palabras que le dicen; por otra parte, una voz demasiado baja puede dar como resultado la distracción respecto al mensaje.

La velocidad verbal tiene también influencia en la comunicación. A veces, cuando una tarea debe realizarse con prontitud, se habla rápidamente. Por el contrarío, la lentitud al hablar puede comunicar una sensación de reposo, o bien, que se está haciendo una reflexión profunda respecto de una idea. Demasiada lentitud al expresarse puede provocar la falta de atención.

Es importante tomar en cuenta que no variar el tono, el volumen y la velocidad verbal puede provocar monotonía y no se aprovechan las posibilidades emocionales que la voz ofrece. En cambio, la diversidad mantiene la atención de quien escucha y le indica al auditorio lo que es importante para la persona que envía el mensaje. Así por ejemplo, cuando se baja repentinamente la voz, las personas oyentes se sienten obligadas a modificar su concentración. Asimismo, dar fuerza a las palabras después de varias frases dichas en voz baja, atrae de nuevo la atención del auditorio. 
Además, el tono, el volumen y la velocidad de las palabras transmiten significados emocionales. Las palabras que pronunciamos son inexpresivas, no obstante, el tono en que se pronuncian puede comunicar, por ejemplo, aprobación o desaprobación, determinación o indecisión, dominio de la situación o temor; debido a que las palabras pueden ser usadas en distintos tonos: sarcástico, respetuoso, amenazante, afectuoso. El lenguaje corporal complementa los significados emocionales expresados verbalmente. Por tanto, se recomienda que la persona intente lograr un dominio de sí misma, de manera tal que no se inhiba la respuesta natural del cuerpo que acompaña la expresión oral del pensamiento. Para ello, debe aprender a relajar su cuerpo, de modo que las respuestas corporales surjan libremente.

Un problema que se puede presentar es la aparición de un conflicto entre el mensaje oral y el físico, lo que se denomina como comunicación de dos canales. Por ejemplo, un profesor o profesora puede intentar con sus palabras, estimular a la población estudiantil para que pregunte u opine, pero su posición, su expresión facial y sus gestos expresan todo lo contrario. Por otra parte, el exceso de gestos y movimientos puede significar un impedimento para la comunicación.

Grant (1988, p. 33-35) sugiere realizar las siguientes actividades relacionadas con la voz y el cuerpo:

1. Analice su propio lenguaje verbal y corporal.

2. Intente dominar sus inhibiciones respecto a la expresión corporal. Escuche música, melódica y rítmica y "piense" que está realmente realizando actividades como: nadar, balancearse, pintar con una brocha grande. Interprete físicamente cada una de estas actividades al ritmo de la música, utilizando todo su cuerpo.

3. Para intentar estar relajado físicamente, mientras realiza los movimientos expresivos corporales, hágase a la idea de que usted, por ejemplo, es una hoja que está flotando sobre las aguas o un árbol balanceado por el viento.

4. Colaborando con otros profesores y profesoras, improvise la dramatización de un cuento que conozcan, tomando parte cada uno y cada una en la historia, acomodando su voz según cada personaje y expresando corporalmente los sentimientos y significados cognoscitivos del cuento.

5. Utilice la pantomima para contar el cuento. Una persona lee el cuento, mientras las demás exponen de forma no verbal las acciones y sentimientos de los personajes. 
Intente esta actividad a fin de vencer las inhibiciones que le impiden utilizar los movimientos expresivos del cuerpo.

6. Lea un cuento a un grupo de niños y niñas. Intente expresar tanto verbal como facialmente las emociones de los personajes. Al tiempo de hacerlo, mantenga su cuerpo relajado, de modo que pueda servirse de él para complementar sus palabras cuando la acción así lo requiera. Repita esta actividad varias veces con diferentes cuentos.

\subsection{Control de palabras}

La palabra es uno de los vehículos más importante para transmitir significados cognoscitivos y emocionales. La comunicación positiva o negativa que transmiten las palabras es un elemento fundamental de la comunicación.

La forma de encontrar las palabras adecuadas está determinada por la manera cómo se ajustan mejor a una situación particular. La pregunta que debe hacerse es ¿estoy empleando las palabras adecuadas para que las personas que escuchan comprendan mi mensaje? Esto significa que lo importante es buscar la claridad de lo que se comunica.

\subsection{Control situacional}

Se pueden enviar mensajes mediante el empleo del color, el tiempo, cosas materiales o artificios tecnológicos. Por ejemplo, la clase y la colocación de los muebles comunican algo; los colores que se utilizan en una habitación o incluso la forma de vestir.

Se sugieren ejercicios como los siguientes:

a) Cuando mire la televisión, observe cómo diferentes personas, por ejemplo, aquellas dedicadas a la política, utilizan variables situacionales como el largo del cabello, el modo de vestirse, objetos como automóviles, animales, familiares, para causar una impresión favorable.

b) Piense en la impresión que usted puede causar en diversas situaciones, considerando aspectos como la forma de llevar el cabello, la forma habitual de vestir, las personas que tiende a elegir, los objetos que le rodean. 


\subsection{Elementos que bloquean el proceso de comunicación}

De acuerdo con Grant (1988) los tres elementos que pueden bloquear el proceso de comunicación son: el enmascaramiento de la conducta, la interpretación y la falta de atención.

\subsection{Enmascaramiento de la conducta}

En las relaciones sociales, es frecuente que las personas que participan presenten una apariencia exterior o fachada que no refleja sus sentimientos o pensamientos. Esta manera de actuar tiene el propósito de presentar una imagen favorable de sí mismas; pueden acomodarse a las normas de conducta establecidas, asociadas con una situación o controlar la conducta de las demás personas participantes en esta situación.

Existen ciertos elementos contradictorios en cualquier proceso de enmascaramiento. Por ejemplo, los mensajes transmitidos oralmente pueden ser opuestos a los mensajes trasmitidos física y situacionalmente. Al respecto señala Grant (1988, p. 49):

En definitiva lo que hace al oyente sensible es atender principalmente a los elementos sutiles e imperceptibles de la comunicación. Es fácil ensartar unas cuantas palabras que enmascaran lo que realmente estamos sintiendo y pronunciarlas con un fingido entusiasmo. Es más difícil mostrar una sensación de ansiedad, de tristeza o de ira en el semblante, adoptando el modelo de expresión apropiado. Pero es casi siempre imposible controlar la tensión muscular, la aparición del rubor en la cara y la nariz, una digestión y respiración pesadas, las arrugas de la frente y cerca de los ojos, las sacudidas nerviosas de manos y rodillas.

En otras palabras, se puede engañar mediante la expresión verbal, pero es casi imposible hacerlo empleando los signos no verbales.

\subsection{Interpretación}

Los mismos estímulos pueden ser percibidos de forma diferente por cada persona. La conclusión a la que se ha llegado, es que gran parte de lo que se percibe es deducido y esta deducción se encuentra determinada por los intereses y las actitudes de la gente. Así por ejemplo, la inseguridad puede hacer que una persona interprete un mensaje como amenaza cuando en realidad no es así. De igual forma, lo que una persona valora, juzga como bueno o malo, gusta o rechaza, puede determinar su modo de captar los mensajes. 
Por otra parte, así como las palabras no tienen el mismo significado para todas las personas, también las expresiones no verbales pueden significar elementos diferentes para cada una.

\subsection{Falta de atención}

Una persona puede participar en una interacción social con pensamientos e intereses poco relacionados con el asunto que se está tratando. Esta situación impide que pueda centrar su atención en lo que se habla. Es decir, su atención varía entre sus propios pensamientos y lo que se discute. Por ejemplo, un estudiante o una estudiante que llega a la clase después de una discusión en la familia, experimenta un pensamiento y una atención que divagan entre la explicación del profesor o de la profesora y el recuerdo de la experiencia que acaba de vivir, surgiendo así una barrera en la comunicación.

Esta conducta de falta de atención puede tomar la forma de anticipación, la cual ocurre cuando quien escucha piensa que sabe lo que la persona que habla va a decir, antes de que realmente lo diga.

Otra forma de conducta que evidencia la falta de atención, es lo que se conoce como espera mental. En este caso, quienes escuchan están mentalmente más enfrascados en la expresión de sus ideas que en lo que el otro o la otra está pensando. En realidad, lo único que hacen es esperar que quien habla haga una pausa, para poder decir lo que está pensando.

Algunas veces, situaciones como el agotamiento mental, el ruido, el calor o la monotonía pueden dificultar que se capten los mensajes.

Gordon (1989) considera que los estudiantes y las estudiantes son notablemente sensibles a los mensajes no verbales que envían sus profesores y profesoras. Aprenden, por ejemplo, a leer la tensión muscular, las expresiones faciales y los movimientos corporales. Si estos mensajes corporales están en conflicto con los mensajes verbales, se puede confundir a quienes escuchan. Además, como ya se mencionó, es prácticamente imposible lograr ser falso con los sentimientos propios. Por lo tanto, se recomienda al profesor y la profesora que cuando se encuentren en el salón de clase, hagan un esfuerzo por concordar sus mensajes verbales y no verbales. 
Es importante señalar también que existen muchos comportamientos que son mensajes que la población estudiantil envía para indicar que algo anda mal, que está experimentando algún problema. Por ejemplo, un estudiante mira por la ventana en lugar de leer; otra nunca juega durante el recreo, sino que se aísla; otro se pasea inquietantemente por el salón y molesta a sus compañeros o compañeras. Cuando el profesor o la profesora recibe este tipo de mensajes, ciertamente no puede, o no debe ignorarlos y esperar que los problemas desaparezcan, decirle a sus estudiantes que sus problemas no son de la escuela o tratar de suprimir el comportamiento con amenazas o castigos.

Por otra parte, aunque con frecuencia es adecuado emplear un lenguaje de no aceptación, cuando un comportamiento del estudiante está causando una situación incómoda, no es apropiado ni útil emplear ese lenguaje cuando el estudiante o la estudiante tiene algún problema. Los muchos posibles mensajes de no aceptación que se pueden enviar, pueden ser clasificados en doce categorías. Estos doce tipos de mensajes tienden a obstaculizar comunicaciones futuras y reducen o inhiben, por completo, el proceso de dos sentidos de la comunicación, que es tan importante para ayudar a la población estudiantil a resolver aquellas situaciones qua interfieren con su aprendizaje. Los doce obstáculos de la comunicación, mencionados por Gordon (1989) son: orden, dirección, mandato; advertencia, amenaza; exhortación, sermón, expresiones como: "deberías" y "tendrías"; aconsejar, proporcionar soluciones o sugerencias; conferenciar, enseñar, dar argumentos lógicos; juzgar, criticar, estar en desacuerdo, culpar; poner apodos, ridiculizar, avergonzar; interpretar analizar, diagnosticar; alabar; tranquilizar, compadecer, consolar, apoyar; probar, preguntar en exceso; retirarse, distraer, ser sarcástico.

\subsection{El empleo del interrogatorio}

El empleo de los interrogatorios cuando el estudiante o la estudiante tiene un problema, con frecuencia actúan como un obstáculo de la comunicación. Esto por cuanto las personas se sienten amenazadas cuando piensan que alguien trata de profundizar demasiado en los sentimientos que no están preparadas para compartir. Generalmente, las personas se cierran como autodefensa cuando sienten que su mundo interno privado está siendo invadido.

Además, las preguntas también pueden desviar la comunicación si son irrelevantes y no están bien enfocadas. La persona que interroga a menudo está adivinando; de modo que 
un elevado porcentaje de sus preguntas estará fuera del objetivo. Esto significa que la persona que tiene el problema debe desviarse y responder de alguna forma o combatir la irrelevancia; por ejemplo: "no, no es por eso que me siento mal".

Así mismo, la mayoría de las preguntas limita la amplia gama de sentimientos o temas que puede comunicar la persona que tiene el problema. Las preguntas dirigen al que habla a referir la conversación lo más cerca de la respuesta solicitada por la pregunta del que escucha y ésta bien puede permanecer fuera del contexto. En efecto, quien pregunta dirige la discusión y lo peor es que no permite que la persona que tiene el problema asuma la responsabilidad de encontrar solución.

Por otra parte, el tipo de mensaje que se envía es muy importante. De esta forma, deben emplearse aquellos mensajes que hacen que las personas se sientan mejor; les aliente a expresarse; les faciliten la expresión de sus sentimientos; propicien el sentimiento de valor propio, el cambio constructivo y reduzcan la amenaza o el temor.

Al respecto, señala Maturana en Eliot (2003), que lo importante no es lo que se entregue, sino cómo lo recibe la otra persona, lo que implica la necesidad de tomar en consideración las posibles consecuencias que la comunicación producirá en las demás personas. Para que los resultados de la comunicación sean satisfactorios, es fundamental el reconocimiento de la validez que se les da a los otros seres humanos, a sus formas de pensar y de sentir, para poder construir procesos de desarrollo en las sociedades.

Ciertamente, el tipo de educación que debería emplearse es una educación más afectiva; no obstante, como bien señala Villarreal (2003), a pesar de que han surgido una variedad de propuestas, tales como la educación holística, el constructivismo y la pedagogía de la esperanza, cuyo propósito es ir más allá de los procesos educativos basados simplemente en el aprendizaje de contenidos, nuestras instituciones educativas mantienen el acento en los conocimientos. Este modelo educativo, explica esta autora, tiene implícito un concepto de comunicación como sinónimo de transmisión de información y una relación basada en el poder, en la cual se asume que el docente o la docente es quien sabe y tiene la autoridad y el estudiante y la estudiante se apropian del saber de quien enseña y asumen un papel de sumisión. 


\section{Cuatro formas de escuchar para ayudar}

Cuatro formas diferentes de escuchar a la población estudiantil para ayudarla cuando tiene problemas, son presentados por Gordon (1989) y de ellas se hace referencia a continuación.

\subsection{Forma pasiva de escuchar (silencio)}

El silencio es un poderoso mensaje no verbal que puede hacer que una persona se sienta aceptada y la alienta a compartir más. Una persona no puede hablar sobre lo que le molesta, si la otra persona es la que habla.

\subsection{Respuestas de reconocimiento}

Resulta de ayuda, especialmente en las pausas, emplear claves verbales y no verbales para señalar que se está atento. A estas claves se les llama "respuestas de reconocimiento"; por ejemplo, hacer una señal con la cabeza, inclinarse hacia delante, sonreír, fruncir el ceño, que empleadas adecuadamente, permiten que la otra persona sepa que realmente está siendo escuchada.

\subsection{Los abrepuertas}

Con frecuencia, las personas necesitan un estímulo adicional para hablar más, para profundizar e, incluso, para empezar a expresarse. Esos mensajes se conocen como "abrepuertas". Algunos ejemplos son: "¿te gustaría hablar más sobre eso?". "Eso es interesante; ¿quiere continuar? "Me interesa lo que estás diciendo". "¿Hay algo de lo que me quieras hablar?"

\subsection{La forma activa de escuchar}

El silencio, las respuestas de reconocimiento, los abrepuertas, a pesar de ser de gran ayuda, tienen limitaciones, por cuanto no proporcionan mucha interacción, ya que la persona que habla es la que realiza todo el trabajo. Asimismo, quien habla no tiene manera de saber, si quien escucha comprende, solo sabe que está escuchándolo.

La forma activa de escuchar requiere de mayor interacción y de muchas más pruebas de que la otra persona no sólo escuchó, sino que además comprendió con exactitud. 
En la forma activa de escuchar, la retroalimentación ofrecida mediante el reflejo, tanto de los sentimientos como el contenido del mensaje es de suma importancia. Un ejemplo de reflejo puede ser: " ¡El problema que se va a armar cuando mi papá se dé cuenta!" Reflejo: " tienes temor de que él se vaya a enojar". Sobre este tema expresan James y Jongeward (1986, p.45).

El escuchar activo, con frecuencia llamado escuchar reflexivo, comprende la retroalimentación verbal del contenido de lo que se dijo o hizo, junto con una conjetura sobre los sentimientos inherentes en las palabras pronunciadas o los actos. Estos se expresan verbalmente. Escuchar de verdad no significa necesariamente estar de acuerdo. Sencillamente quiere decir aclarar y comprender los sentimientos y puntos de vista de otra persona.

Desde la teoría del Análisis Transaccional, sin condenar o condonar, el estado Adulto del yo escucha tanto el contenido como los sentimientos que la otra persona expresa desde su estado Niño del yo.

Gordon (1989) menciona que para que la forma activa de escuchar sea efectiva, los profesores y las profesoras deben tener actitudes como: confianza en la capacidad de sus estudiantes para resolver sus problemas (el propósito de la forma activa de escuchar es facilitar el encuentro de soluciones); aceptar los sentimientos de sus estudiantes por diferentes que sean de los que él o ella piensa que su estudiante debería tener; entender que con frecuencia esos sentimientos son transitorios; debe querer ayudar a sus estudiantes con problemas y dedicar tiempo para esto; no debe dejarse atrapar por los sentimientos de sus estudiantes al punto de que pierda la individualidad; es decir, debe experimentar los sentimientos como suyos, sin permitir que se conviertan en suyos; debe entender que pocas veces sus estudiantes empiezan por compartir el verdadero problema que están viviendo; debe respetar la naturaleza privada y confidencial de lo que exprese su estudiante sobre él o ella y su vida.

La formar activa de escuchar ayuda a las personas a manejar los sentimientos violentos. La expresión de estos sentimientos les ayuda a liberarse de ellos. Mediante esta forma de escuchar, las personas comprenden que no necesitan temer a sus propias emociones y que los sentimientos no son malos. Facilita la solución del problema por la persona misma. 
Cuando el profesor o la profesora escucha de forma activa, sus estudiantes se dan cuenta de que sus puntos de vista, opiniones, sentimientos e ideas han sido comprendidas, lo que a la vez, permite que estén más dispuestos y dispuestas a escuchar las opiniones e ideas del profesor o de la profesora. La forma activa de escuchar promueve una relación más significativa entre las personas. Cuando la persona es escuchada experimenta un sentimiento de valía, lo que aunado a la satisfacción de ser comprendida, hace que sienta cariño por la persona que la escucha.

Señala Gordon (1985, p. 96):

el escuchar empáticamente, caminar unos cuantos pasos con el alumno por el camino de la vida, es un acto de interés, respeto y amor... Más aún, cuando las relaciones entre el maestro y los alumnos producen interés, respeto y amor mutuos, los problemas de "disciplina" disminuyen de una manera importante.

Esta autora explica cómo confrontar a la población estudiantil con mayor posibilidad de influir en ella, a fin de que modifique su comportamiento y con una menor posibilidad de dañar la imagen de sí misma o la relación que tiene con ella.

Para iniciar, el profesor o la profesora debe expresar cómo se siente a causa del comportamiento de sus estudiantes, o la forma tangible como éste lo afecta; por lo tanto, el mensaje debe tener la forma de un mensaje yo y no la de un mensaje tú. Por ejemplo: "(yo) no puedo trabajar cuando primero tengo que recoger todos los materiales que dejaron en desorden." "(yo) me siento verdaderamente abrumado (o abrumada), cuando hay tanto movimiento en el salón."

Mensajes como éstos comunican lo que el profesor o la profesora está experimentando, mientras que el mensaje tú, es un juicio negativo sobre el estudiante o la estudiante. Por ejemplo: "estás actuando como un bebé". Los mensajes "yo" contienen tres criterios importantes para una comunicación eficaz: tienen gran posibilidad de promover la disposición a cambiar, contienen una evaluación negativa mínima y no dañan la relación.

Una descripción que no culpa ni juzga lo que es inaceptable, es un buen comienzo para un mensaje "yo". Cada uno de estos mensajes "yo" eficaces empiezan con un "cuando". Por 
ejemplo: "Cuando me encuentro papeles tirados en el suelo..." " Cuando veo libros nuevos con las páginas rotas..."

El segundo componente del mensaje "yo" es por lo general el más difícil de enviar. Señala el efecto tangible o concreto del comportamiento específico descrito en la primera parte del mensaje. Ejemplo: "cuando las pinturas no son devueltas al armario (descripción sin juicio), pierdo mucho tiempo recogiéndolas y guardándolas..." (efecto tangible).

La tercera parte del mensaje "yo" debe expresar los sentimientos generados en el profesor o la profesora. Ejemplo: "cuando pones los pies en el pasillo (descripción del comportamiento), me puedo tropezar (efecto tangible) y me da temor caerme y lastimarme (sentimiento)".

Los mensajes "yo" producen menos posiciones defensivas en las personas que los mensajes tú; no obstante, a nadie le gusta escuchar que su comportamiento le está causando molestia a alguien; no importa la manera cómo se formule el mensaje, por lo que se recomienda que después de la confrontación, se pase a la forma activa de escuchar, para permitir que la persona encuentre una forma aceptable de solucionar la situación. Además, esto demuestra la comprensión y aceptación del profesor o de la profesora de las relaciones con sus estudiantes.

Parece que el empleo de los mensajes "yo" influye para que los estudiantes y las estudiantes, con el tiempo, también empiecen a enviar mensajes sinceros a sus compañeros y compañeras, profesores y profesoras.

Igual que en algunos enfoques, tales como el humanista y el de Virginia Satir, también villarreal (2003), considera la comunicación como relación e interrelación entre las personas, reconociendo los dos tipos de interacciones presentados por Vásquez (1966) : las verticales y las horizontales. Se explica que las interacciones verticales se presentan en el marco de una estructura asimétrica en relación con el poder, mientras que en las interacciones horizontales la participación es más equitativa, más amplia y flexible y, por lo tanto, la que debería promoverse en diversos ámbitos, sobre todo en el educativo.

Considero que las relaciones interpersonales entre los participantes y las participantes de los procesos educativos, podrán ser más eficaces y placenteros, cuando se comprenda que 
todas las personas aprendemos unas de otras y cuando predomine el dominio de la comunicación afectiva. Entonces, las relaciones humanas podrán ser más cálidas y esto redundará en beneficio, tanto del crecimiento personal como de los logros en el proceso de enseñanza-aprendizaje.

En la educación se debe propiciar el diálogo y la reflexión, ya que mediante éstos, las personas pueden construir conocimientos y encontrar formas de desarrollo personal y social. Ese es el sentido de la comunicación. Pero, como bien lo plantea Maturana en Eliot (2003), las comunicaciones se han encargado muchas veces de propiciar personas solas, esclavas y abandonadas, que no se detienen a hacer reflexiones y esto las hace vulnerables, más fáciles de dominar y de ir cayendo en un abismo de soledad. Solamente teniendo en cuenta a la otra persona como legítimo ser humano en la convivencia, nos comunicamos realmente $y$, eso es el amor, mediante el cual se construyen vínculos valiosos que permiten salvar ese abismo de la soledad.

\section{Conclusiones}

La función más importante del proceso de comunicación es el desarrollo de las relaciones entre las personas.

Las relaciones humanas siguen una secuencia que va desde una etapa básica de reconocimiento, pasando por la aceptación y el afecto, hasta una etapa más profunda de comprensión.

Para que el proceso de comunicación, entendido como interacción, sea más efectivo, es importante tomar en cuenta aspectos como los siguientes:

Toda conducta implica comunicación, es decir, tiene valor de mensaje, por lo tanto, afecta positiva o negativamente la relación de las personas participantes. Lo anterior sugiere que se deben evitar formas de comunicación como el rechazo, la descalificación y fingir síntomas.

Emplear la asertividad en la comunicación produce relaciones humanas más saludables; cada persona se responsabiliza de lo que expresa y de la forma cómo lo hace, acepta y Volumen 5, Número 2, Año 2005, ISSN 1409-4703 30 
respeta sus derechos y los derechos de las demás personas y, por lo tanto, evita conductas inapropiadas como la agresión, la intimidación y la manipulación.

Para que la comunicación sea funcional, debe ser clara, lo cual significa que la persona que escucha atiende el mensaje recibido, el lenguaje corporal, las expresiones faciales y el contexto en donde se desarrolla la relación; y por otra parte, quien habla trata de que todos los elementos del mensaje, lleven una misma dirección; es decir, que la emoción y el comportamiento concuerden con el mensaje enviado.

El empleo de formas adecuadas de escuchar también contribuye a mejorar el proceso de comunicación, entre ellas el buen empleo del silencio; las respuestas de reconocimiento; los estímulos adicionales para iniciar o profundizar los mensajes; el reflejo de sentimientos o contenidos y el uso de los mensajes "yo".

El proceso de comunicación está presente y afecta todos los ámbitos de la convivencia humana: el familiar, el educativo, el laboral, el social... de modo que todos los esfuerzos que se realicen por comprender mejor y perfeccionar este proceso, redundarán en beneficio de las relaciones humanas.

Una comunicación efectiva es aquella que permite que el ser humano se desarrolle; que promueve la interrelación auténtica entre las personas ;que facilita la expresión de los pensamientos y los sentimientos de los participantes y las participantes de las sociedades; que promueve la obtención y difusión de conocimientos, construir una identidad y una cultura, reflexionar sobre nuevas formas de percibir y dar significado a la existencia, acercarse más a ideales como la libertad, la justicia, la igualdad y la espiritualidad. Es síntesis contribuir con el progreso de la humanidad. 


\section{Referencias}

Bateson, G y Ruesch, J. (1984). Comunicación. La matriz social de la psiquiatría. Barcelona: Paidos.

Borden, G y Stone, J. (1982). La comunicación humana. Buenos Aires: El Ateneo.

Brusco, A. (2001). La comunicación como punto de partida. Recuperado el 11 de junio de 2005, de www.vocesensilencio.org.ar $/$ modules.php?name $=$ News\&file $=$ articles\&sid $=176=29 \mathrm{k}$

Eliot, TS. (2003). ¿Dónde está la vida que hemos perdido en vivir? ¿Dónde la sabiduría que hemos perdido en conocimiento? Comunicación y desarrollo humano. Recuperado el 10 de junio de 2005, de http://www.uap.edu.ar/signos/art./

Gordon, T. (1989). Maestros eficaz y técnicamente preparados. México: Diana.

Grant, H. (1988). El dominio de la comunicación educativa. México: Amaya S.A.

James, M y Jongeward, D. (1986). Nacidos para triunfar. México: Fondo Educativo Interamericano.

Janda, L. (1998). Los tests de autoconocimiento y superación. Barcelona: Robinbook.

Neidharet, J, Weinstein, M y Conry, R. (1989). Seis programas para prevenir y controlar el estrés. Madrid: Deusto.

Pérez, J. (1986). Terapia familiar en el Trabajo Social. Teoría y práctica. México: PAX.

Riso, W. (1988). Entrenamiento asertivo. Aspectos conceptuales, evaluativos y de intervención. Medellín: Rayuela.

Satir, V. (1980). Psicoterapia familiar conjunta. México: Prensa Médica Mexicana.

Satir, V. (1988). Nuevas relaciones en el núcleo familiar. México: PAX.

Villarreal, A. (2003). Comunicación en el aula reproduce inequidad. Revista Electrónica Actualidades Investigativas en Educación. 3(2). Recuperado el 21 de junio de 2005, de http://revista.inie.ucr.ac.cr

Watzlawick, P. (1991). Teoría de la comunicación humana. Barcelona: Herder. 